\title{
Consultoria-Geral da República
}

PR 19.860-64 - N 159, de 20 de maio de 1964. Restitui ao Excelentissimo Senhor Presidente da República processo que trata da suspensão dos direitos políticos de Alberto Guerreiro Ramos e sua conseqüência em relaçĩo ao cargo que o mesmo ocupa no Departamento Administrativo do Serviço Público, de Técnico de Administração. Esclarece que a matéria foi, com aç̂rto, apreciada pelo Senhor Consultor Jurídico do D.A.S.P., Dr. Cienicio da Silva Duarte, em parecer abaixo, cujas conclusões a referida Consultoria adota, integralmente, pelos seus jurídicos e jiidiciosos fundamentos, por isso que em perfeita consonância com a legislação especifica, aplicável ao caso, o Ato Institucional e sua respectiva regulamentação. "De acôrdo". Em 27 de maio de 1964 '(Rest. ao DASP, em 1-6-64).

\section{PROCESSO N $\mathrm{N}^{\circ} 4.816-64$}

- A suspensão dos direitos politicos tem como conseqüência o afastamento do exercício de cargo público, por ser êsse exercício um dos direitos políticos.

- Direitos politicos - seu conceito na doutrina e na legislação. - Interpretação do $\S 11^{\circ}$ do artigo $7^{\circ}$ do Ato Institucional, baixado pelo Comando Supremo da Re-
volução.

- Os atos decorrentes do exercício dos podêres excepcionais de que cogitam os arts. $7^{\circ}$ e 10 do Ato Institucional, transferindo-se ao Presidente da República, por fôrça do mesmo diploma, permitem, durante o processo revolucionário, a revisão por essa autoridade, se assim entender conveniente.

- Da vigência do ato de suspensão dos direitos políticos até a decisão do processo de investiga-
Şão sumária, faz jus o funcionário público, estável ou vitalicio, a vencimento ou remuneração proporcional ao tempo de serviço, como se se tratasse de uma disponibilidade provisória.

\section{PARECER}

I

Alberto Guerreiro Ramos, Técnico de Administração dêste Departamento, de cujo cargo é titular efetivo em gôzo de estabilidade, teve os seus direitos políticos suspensos, pelo prazo de dez anos, por fôrça do Ato $n^{2} 4$, de 13 de abril último, do Comando Supremo da Revolução, publicado no Diário Oficial do dia 14 subseqüente.

2. O interessado se achava legalmente afastado do exercicio do cargo, nos têrmos do art. 79 n ${ }^{2}$ VIII, do Estatuto dos Funcionários Públicos Civis da União (Lei $\mathrm{n}^{*} 1.711$, de 28 de outubro de 1952), desde que, na quali: dade de suplente de deputado federal, pelo Partido Trabalhista Brasileiro, 52. ção do Estado da Guanabara, fôra convocado para exercer o respectivo man-
dato legislativo.

3. Em decorrência dessa restrição de direito, foi o funcionário apresentado a êste Departamento, através do Oficio $\mathrm{n}^{2}$ 96-G do $\mathrm{Sr}$. Primeiro Secretário da Câmara dos Deputados, datado de 28 de abril próximo findo, uma vez que aquela Casa do Congresso Nacional considerou suspenso, ex $v i$ do referido Ato, o seu mandato de Deputado Federal.

4. O Serviço de Administração do DASP, ao receber o ofício acima mencionado, deseja saber qual a situação funcional do interessado, para o que solicitou a audiência desta Consultoria Jurídica, esclarecendo, entretanto, quz. sôbre hipótese semelhante, já opinou o 
Dr. Consultor Juridico do Ministério do Trabalho e Previdência Social, cujo parecer foi aprovado pelo titular daquela Pasta e encaminhado à consideração do Dr. Consultor-Geral da República, por se tratar de matéria cie elevado interêsse da administração, a ser decidida de maneira uniforme.

5. Tendo, assim, presentes os dados da consulta, passamos a opinar a re'speito.

\section{II}

6. E fora de dúvida que a suspensão de direitos politicos acarreta, por via de conseqüência, a impossibilidade de exercício de cargo público, durante todo o periodo a que se refere a interdição de tais direitos.

7. E que, como bem demonstrou o Dr. Consultor Jurídico do Ministério do Trabalho e Previdência Social, no parecer retrocitado, com apoio em eminentes tratadistas, entre os direitos politicos se inclui, precisamente, 0 ie ccupar e exercer cargos e empregos públicos. Essa orientação doutrinária $e$ legislativa, tradicional no nosso direito positivo, tem larga aceitação na com. munis opinia, por isso que, de fato, confundindo-se os direitos politicos com os de cidadania, onde só se admite o exercicio de cargo público pelos cidaA dãos de Estado, a suspensão de tais direitos importa, automàticamente, no afastamento dêsse exercício, pela capitis diminutio outorgada.

8. Não se conceberia que, pela suspensão do jus civitatis durante certo periodo, pudesse o funcionário público continuar em pleno exercício de suas funções, se, para ingresso nelas, o Es. tado o condicionara ao gôzo dêsse direito. Quando a lei (Estatuto dos Funcionários Civis da União, art. 22, $\mathrm{n}$ ? III) exige, para a posse em cargo público, o gôzo dos direitos políticos, quer com isso significar que a titularidade dêsses direitos é condição 1mprescindivel para o exercício do cargo desde que não teria sentido essa exigência para a posse, se, após a investidura, pudesse ocorrer a sua perda ou suspensão com a continuidade de exer^ cicio.
9. Tanto é assim que a nossa Lel Maior impõe como corolário da perda dos direitos políticos a do cargo ou função pública (Constituição Federal, art. 136). Se é omissa em relação à pena de suspensão de tais direitos, é porque as hipóteses que contempla como originários dessa suspensão poderian, conforme o seu tempo de duração, ou determinar a suspensão do exercicio. durante o período de interdição dêsse direito, ou a perda do respectivo cargo (Constituição Federal, art. 135, § 1\%, ns. 1 e II).

10. Não padece dúvida, pois, que a suspensão dos direitos políticos $1 \mathrm{~m}$ possibilita o exercício do cargo píblico durante o periodo da interdição, pelo motivo óbvio, já esclarecido, de que constitui direito politico o exercício dessa função pública. Não bastassemn as autoridades citadas pelo ilustre Consultor Juridico do Ministério do Trabalho e Previdência Social, poderiamos acrescentar uma infinidade de pronunciamentos no mesmo sentido, como se vê, verbi gratia, de José Naufel, Nôvo Dicionário Juridico Brasileiro, Konfino $V^{\circ}$ Direito Politico; Pedro Nunes, Dicionário de Tecnologia Juridica, Fraitas Bastos, $3^{*}$ ed., 1956, v Direito Politico; Guilhermo Cabanellas, Dicionario de Derecho Usual, Buenos Aires, v ${ }^{9}$ Derechos Politicos; Marcelo Caetano, Mianual de Direito Administrativo, 1960. $5^{\circ}$ ed., págs. 443 e 446; Dardeau de Carvalho, Repertório Enciclopédico do Direito Brasileiro V Cidadania, $\mathrm{n}^{\circ} 11$. Ministro Vitor Nunes Leal, Elementos do Estado, artigo in Revista Forense, vol. 96 , págs. 25 e segs.; José Cretella Túnior, Direito Administrativo do Brasil. Rev. dos Tribunais, 1958, vol. II, página 231, in fine, a 233, e João Barbalho, Constituição Federal Brasileira. 2* ed., 1924, págs. 394, in fine, e 395.

11. Aliada a essa orientação doutrinária, o nosso direito positivo também a consagra, consoante dispunha o parágrafo único do art. $3^{\circ}$ do Decreto-lei $n^{2}$ 389, de 25 de abril de 1938, zuja redação é a seguinte:

"Săo direitos politicos o de scr eleito ou eleitor, na forma da Cons- 
tituição, e o de ocupar e exercer cargos e empregos públicos ou ou. tros que a lei atribua exclusivamente a brasileiros" (o grifo aão é do original).

12. Nem é outro o conceito da Lei $n^{\circ} 818$, de 18 de setembro de 1949 , onde se lê, no seu art. 38:

"São direitos políticos aquêles que a Constituição e as leis atri. buem a brasileiros, precìpuamente - de votar e ser votado" (é nosso - grifo).

13. Ora, se o exercício de cargo público é direito privativo de brasileiro, segue-se que se compreende cntre os direitos políticos, por fôrça do disposto no comando jurídico transcrito no item anterior, o desempenho de tais cargos.

14. Estabelecido êsse ponto, de fundamental importância para o esclarecimento da situação funcional do interessado, passemos a examinar as conse. quiências juridicas que dai advém.

\section{III}

15. Pela interpretação do Ato Institucional de 9 de abril do corrente ano baixado pelo Comando Supremo da Revolução, o funcionário público, alcançado pela suspensão de seus direitos políticos, terá, como conseqüência ime diata, e até que se proceda à investigação sumária de que cogita o $\$ 10$ do art. $7^{\circ}$ do referido Ato Institucional:

a) a perda definitiva dêsse cargo, se não estiver em gôzo de estabilidade ou vitaliciedade;

b) se estável ou vitalício, o afasta. mento do exercício do cargo, do qual será demitido ou nêle declarado em ciisponibilidade ou aposentado, com vencimentos e vantagens proporcionais ao tempo de serviço, conforme o resılitado da investigação sumária a que se procederá, em obediência ao citado $\S 1^{\circ}$ do art. $7^{\circ}$, regulamentado pelo Decreto número 53.897, de 27 de abril de 1964 .

16. Do que se contém na alinea $b$ do item precedente, verifica-se que funcionário estável ou vitalício, de quem se suspenderam os direitos politicos, será automàticamente indiciado devendo constituir-se o respectivo processo de investigação sumária a fim de que a Comissão Geral de Investigação, criada pelo art. $1^{\circ}$ do Decreto $\mathrm{n}^{\circ} 53.897$, de 1964, conclua pela aplicação ou não de alguma das sanções previstas no $\S 1^{\circ}$ do art. $7^{\circ}$ do Ato Institucional, sendo o processo, em conseqüência, submetido ao Presidente da República (Decreto $\mathrm{n}^{\circ} 53.897$ citado, art. $6^{\circ}$ ), que decidirá a respeito.

17. Ao funcionário público, estável ou vitalicio, a quem se haja aplicado a pena de suspensão de direitos politicos, é evidente que, pelas razões que motivaram a interdição de direitos, Jo. gicamente se aplicará uma das sanções previstas no supra-referido $\S 1^{\circ}$ do artigo $7^{\circ}$ do Ato Institucional. $\dot{\mathrm{E}}$ uma presunção juris tantum, vale dizer que cede a prova em contrário, mas essa só prosperará com a inaplicabilidade de uma daquelas penas, se, em consequiência, determinar a revisão do ato anterior de suspensão dos respectivos direitos politicos.

18. E que a defesa produzida pelo indiciado, nos têrmos do art. 5\% do Decreto $n^{\circ}$ 53.897, de 1964 , remontando aos fatos ou circunstâncias que determinaram, a juizo do Comando Su. premo da Revolução ou do Presiderıte da República, a interdição de direitos poderá, em determinados casos, - de tal modo impressionar a Comissão Geral de Investigações que essa entenda do seu dever sugerir a revisão do ato anterior que ocasionou a suspensão dos direitos politicos.

19. Não se argüia que o ato de suspensão de direitos politicos é insuscetivel de revisão. Não o seria por qualquer outra autoridade que não Presidente da República, e mesmo por êste, após o encerramento do processo revolucionário. Mas, dentro dêle, seudo a competência inicial do Comando Supremo da Revolução transferida ao Presidente da República, por fôrça do mesmo Ato Institucional, nada impede que essa autoridade, e só ela, reveja, quer os atos que haja pessoalmente praticado, quer os da alçada inicial 
do Comando Supremo da Revolução, que lhe foram taxativamente transfeferidos. Essa conclusão deriva do principio da identidade de competència e que assegura, a quem ten podìres para praticar determinado ato, a prerrogativa de revê-lo.

20. Essa competência revisionista do Presidente da República é perfeitamente cabivel, durante o processo revolucionário, e êste ainda se acha em plena evolução, tanto que se deferitı àquela autoridade a continuidade da prítica dos podêres excepcionais previstos 110 Ato Institucional, que só se encerrarão após os prazos a que se referem os arts. $7^{\circ}$ e 10 dêsse diploma.

21. Não assim outro Presidente àa República, que sucedesse ao atual, já após a ultimação do processo revolucionátio, com a volta do país a sua normalidade, porque a êste se não deferira a competência incomum de que cogita - Ato Institucional, cuja eficácia, nesse pasșo, então se exaurira.

22. Nem seria defensável que se pretendesse, após a verificação do possivel equivoco de uma pena, - se fôr ? caso - segundo as conclusões da Comissão Geral de Investigaçōes, ouvidio - Conselho de Segurança Nacional e a juizo do Presidente da República, - se eliminassem os meios de reparação. o que constituiria atentado grave ao D:reito, no seu valor mais fundamental -. a Justiça.

23. E curial de que essas considerações só têm razão de ser na possibilidade de um equivoco. que se constatasse em tôda a sua evidência.

\section{IV}

24. Da entrada em vigor do ato de suspensão dos direitos politicos do funcionário público, estável ou vitalício, até a decisão do Presidente da República, após a investigação sumária prevista no $\S 1^{\circ}$ do art. $7^{\circ}$ do Ato Ins- titucional, regulamentado pelo Decreto $\mathrm{n}^{2}$ 53.897, de 1964, em que o interessado terá de afastar-se do cargo de modo provisório até aquela decisão, cumpre examinar quais as vantagens pecuniárias a que terá direito.

25. De logo se verifica, grosso modo, que alguma lhe terá de ser reconhecida, do momento em que, mesmo no caso do $n^{\circ}$ II do art. 135 da Constituiçãn Eederal, em que, enquanto durarem os cfeitos da condenação, the serão suspensos os direitos politicos, faz jus a um têrço do vencimento ou remuneração, se a pena não determinou demissão (Estatuto dos Funcionários Públicos Civis da União, art. 122, n IV).

26. Paréce-nos que, se há uma presunção jutis tantum da aplicabilidade de uma das sanções previstas no $\S 1^{\circ}$ do art. $7^{\circ}$ do Ato Institucional, após a investigação sumária a que ali se refere, como acima se esclareceu, durante o afastamento provisório sıria de deferir-se ao funcionário vencimento ou remuneração proporcional ao respectivo tempo de serviço, como uma disponibilidade provisória, pois essa, afinal, será a pena mais leve que the poderá ser cominada. Se, entretanto. nenhuma sanção se lhe haja de impor, - que só poderá ocorrer com o anulamento do ato anterior de interdição de direitos, como acima se justificou, a diferença do que deixou de receber lhe será, então, restituida.

27. São essas as considerações que se nos afiguram oportunas a respeito do assunto, as quais, se aprovadas pelo Sr. Diretor-Geral, conviria fôssem cubmetidas à apreciação do Dr. ConsultorGeral da República, em face do evidente interêsse geral de que se reveste a matéria.

\section{E o nosso parecer.}

\section{S.M.J.}

Brasilia, em 11 de maio de 1964 . Clenicio da Silva Duarte, Consultor Juridico. 


\section{Departamento Administrativo do Serviço Público}

\section{DIVISAO DO REGIME JURIDICO DE PESSOAL}

\author{
PROCESSO N*25.061-63
}

\section{PARECER}

No anexo processo, C'onceição No. gueira da Gama, Tesoureira-Auxiliar interina, $1^{\text {* }}$ categoria, do Ministério da Fazenda, solicita efetivação com funmento nas Leis $\mathrm{n}^{\circ} 4.242$, de 1963 e 4.054 de 1962.

2. Para tal fim, juntou uma certidão de tempo de serviço expedida pela Superintendência da Moeda e do Crédits. relativa ao periodo de 8 de outubro de 1953 a 6 de junho de 1962, conetando da mesma que a sua admissão se processou através de contrato de trabalho, regido pela legislação trabalista (fls. 15).

3. Em se tratando de tempo de serviço para fins da Lei $n^{\circ} 4.054$, de 1962, êste Departamento tem julgado mais acertado adotar-se o critério recomendado pela Lei $n^{\circ} 2.284$, de 1954 .

4. Sucede que, para os fins previstos na Lei $n^{\circ} 2.284$, de 1954 , não foi computado o periodo de tempo prestado mediante contrato trabalhista, o qual, dessa forma, não poderá também $\mathrm{s}^{\wedge} \mathrm{r}$ considerado para os fins previstos na Lei $\mathrm{n}^{\circ} 4.054$, de 1962

5. Com êstes esclarecimentos, proponho a restituição do processo ao $\mathrm{M}$ inistério da Fazenda.

Brasilia, 12 de fevereiro de 1964. Luiz de Lima Cardoso - Diretor da Divisão do Regime Juridico do Pessoal.

De acôrdo. - André Carrazoni Diretor-Geral.

Em 14-2-64. - D. O. de 13-4-64.

\section{PROCESSO Ne 20.945-63}

\section{PARECER}

Consulta a Comissão de Acumulação de Cargos se existe impedimento legal no exercicio de dois cargos de magistério, no mesmo estabelecimento de ensino e de idênticas disciplinas.

2. A primeira vista, parece não dar margem à dúvida a hipótese aventada, porquanto se trata de dois cargos de magistério em que se ensinam as mesmas disciplinas dentro de horários nâturalmente compativeis.

3. A rigor, óbice legal não existe, salvo o pronunciamento do $\mathrm{Sr}$. Consultor-Geral da República, Dr. A. Gonçalves de Oliveira, no Proc. P.R. número 2.855-57 (Parecer $\mathrm{n}^{\circ}$ 213-Z), em quc afirmou ser "licito no Chefe do Executivo, a quem se reconhece a oportunidade das nomeaçōes (Parecer número 36-V, em meus Pareceres do Consultor-Geral da República, volume único, setembro de 1954 a fevereiro de 1955 pág. 193); o zêlo pela eficiência dos serviços; o poder de expedir regulamentos, na interpretação do citado preceito constitucional (art. 185), declarar. visando aos magnos interêsses do ensino, como the foi representado, que os regulamentos de concursos, nas faculdades federais, ainda que autárqui. cas, não admitem à inscrição de candidato que já lecione, em caráter $e^{f} e-$ tivo, no mesmo estabelecimento". O argumento fundamental dêsse impedimento foi o de obstar que um só professor titular de duas cátedras tivesse dois votos na congregação. Dai resultou o Decreto $\mathrm{n}^{\circ} 976$, de 11 de maio 
de 1962, que proibiu "a inscrição cm concurso, para cargo de magistério em estabelecimento oficial de ensino secundário ou superior, de candidato que seja ocupante efetivo de cátedra 110 mesmo estabelecimento".

4. Assin, o preceito dispôs para o futuro, quando afirmou que "não scrá admitida a inscrição em concurso, para cargo de magistério em estabelecimento oficial de ensino secundário ou superior, de candidato que seja ocupante efetivo de cátedra no mesmo estabele. cimento", regulamentando, no dizer do $\mathrm{Sr}$. Consultor-Geral da República, uma expectativa de direito, porquanto "direito sòmente o têm os que, atualmente, exercem duas cátedràs, por concurso, em uma mesma Escola", situação esta que ficou expressamente ressalvada.

5. Não existe, entanto, qualquer proibição fora dessa hipótese, nem legal, nem regulamentar, ainda por que não subsistiria, fora do caso dos catedráticos, o motivo básico que ditou a norma expressa no aludido Decreto $\mathrm{n}$ ? 976 , de 1962.

6. Não obstante, no entender desta Divisão, antes de impedir a inscriçáo em concurso em outra cátedra poderia, clata vênia, a Administração disciplinar o assunto da composição das congregações dentro do espirito daquele $\mathrm{Pa}$ recer do $\mathrm{Sr}$. Consultor-Geral da $\mathrm{Re}$ pública, em que ficasse expresso, nos Regulamentos das Unidades de Ensino, que o titular de duas cátedras só tivesse direito a um voto na Congregação e, se possivel, a alteraçăo do quorum nesses casos especiais.
7. Dada a natureza do assunto, seria de tôda a conveniência se ouvisse a Consultoria Juridica dêste Departamento.

Brasilia, 6 de janeiro de 1963. - Ao $\mathrm{Sr}$. Consultor Juridico para opinar. André Carrazzoni, Diretor-Geral. Em 8 de janeiro de 1964.

Senhor Diretor-Geral.

Ao restituir-lhe o presente processo. cumpre-me ressaltar que nẫ vejo qualquer impedimento legal no exercício simultâneo de dois cargos por parte de um servidor e num mesmo estabelecimento de enșino, desde que satisfaça êle às duas condições básicas previstas no art .185 da Constituição; correlação de matérias e compatibilidade de horário.

2. O que não me parece perfeito, $e$ êste deve ser devidamente disciplinado. é que uma professor, nessa situação, se manifeste com duplicidade perante a congregação do respectivo estabelecimento.

3. Se assim fôsse disposto, não haveria, realmente, necessidade de impedir-se a inscrição de candidato a um concurso para provimento de determinada cadeira só pelo fato de já professorar êle no mesmo educandário, como se fêz no Decreto $n^{\circ}$ 976, de 1962.

4. Dessa forma, concordo com o parecer da Divisão do Regime Juridico do Pessoal.

Brasilia, 21 de janeiro de 1964 . Luiz Rodrigues, Consultor-Jurídico. 


\section{Comissão de Acumulação de Cargos}

\section{PROCESSO $\mathrm{N}^{2} \quad 318-64$}

Militar da Ativa sòmente poderà exercer cargo público de magistério mediante transferência para a reserva não remunerada.

PARECER

Hélio Mendes, Capitão-Tenente Médico da Marinha, consulta se lhe seria possivel exercer o cargo de Professor de Medicina na Faculdade de Medicina da Universidade de Santa Catarina.

2. Nos têrmos do art. $20, \mathrm{n}^{2} \mathrm{~V}$. da Lei $\mathrm{n}^{\circ}$ 1.316-1951, os militares sòmente podem exercer cargos de magistério em estabelecimentos particulares, quando expressamente licenciados para êsse fim. Em se tratando, porém, de estabelecimento oficial de ensino, o $\S 5$ ? do art. 182 da Constituição determina a perda dos proventos de seu pôsto ao militar que perceba remuneração de outro qualquer cargo civil, permanente ou temporário.

3. Por outro lado, a investidura do Militar no cargo de magistério civil pretendido deveria ser precedida de transferência do interessado para a re serva, nos têrmos do $\S 3^{\circ}$ do mesmo art. 182 da Constituição.

4. A vista do exposto não ncs parece viável a acumulação pretendida, a menos que o interessado se sujeite àquelas restrições de transferência para a reserva não remunerada.

Assim entendemos S.M.J.

C. A. C., 14 de fevereiro de 1964. Célio Fonseca, Relator. - José Metri. ros. - Zola Maria Fraga. - Aluisio Xavier Moreira. - Corsindio Mon teiro da Silva.

Submeto, nos têrmos do $\S 3^{\circ}$ do art. 15 , do Decreto $\mathrm{n}^{\circ} 35.956$, de 2 de agôsto de 1954, o presente parecer à aprovação do Sr. Diretor-Geral do D.A.S.P.

Brasilia, 21 de fevereiro de 1964. José Medeiros, Presidente de Comissão de Acumulação de Cargos.

Aprovo - Em 21 de fevereiro cie 1964. - André Carrazzoni.

Diário Oficial de 27-4-64.

\section{PROCESSO No $13.931 / 63$}

E lícita a acumulação do cargo de Médico do I.A.P.I. com o die Médico-Auxiliar do Hospital das clinicas, da Faculdade de Medicina da Universidade de São Paulo, tendo em vista a natureza didática de suas atividades, de conformidade com a Lei Estadual, $n^{\circ} 6.784$, de 3-4-62.

\section{PARECER}

Para fins da homologação prevista no art. 17 do Decreto $\mathrm{n}^{\circ} 35.956$, de 2-3-54, o Instituto de Aposentadoria e Pensões dos Industriários (I.A.P.I.) cncaminhou a esta Comissão o anexo processo, que trata da acumulação, por parte de Ignácio Dondici Ruiz, los cargos de Médico daquela autarquia e de Médico-Auxiliar do Hospital das Clinicas da Faculdade de Medicina da Universidade de São Paulo.

Em seu art. 185, a Constituição $\mathrm{Fe}$ deral permite o exercicis cumulativo de um cargo técnico-cientifico, como tal reconhecido o de Médico, com outro de magistério, desde que haja, entre sles. correlação de matérias e compatibilidades de horários. 
Dêsse modo, há que se investigar, inicialmente, a natureza do cargo de Médico-Auxiliar do Hospital das Clinicas, o qual, uma vez caracterizado como do magistério, deverá apresentar a necessária correlação de matérias $\mathrm{ccm}$ - de Médico do I.A.P.I.

A Lei Estadual $n^{2}$ 6.784, de 3-4-62, publicada a 4 seguinte, estabelece em seus arts. $1^{\circ}$ e $2^{\circ}$ :

"Art. 1" Os médicos qua cxercem funçốes consideradas de auxilia: de ensino no Hospital das Clinicas, da Faculdade de Medicina da Universidade de São Paulo, ficam distribuidos nas seguintes categorias:

\section{I - Médicos-Auxiliares;}

II - Médicos-Adjuntos;

III - Médicos-Assistentes.

Art. 2: As funções de Miédicos-Auxiliares, Médicos-Adjuntos e Médicos-Assistentes serão especifidas pelo Conselho de Administração do Hospital das Clínicas" (o grifo não é do original) .

A Seção do Pessoal do aludido Hospital, instruindo processo idêntico, cob $\mathrm{n}^{2}$ 1.504-64, do interêsse de Mauricio Crinberg, juntou cópia de decisão do Conselho de Administração daquele estabelecimento, nos seguintes têrmos:

"O Conselho de Administração opina que a função de ensino decorrente da situação de Assistente Extranumerário da Faculdade de Medicina, constante dos arts. 53 e 79 do Regulamento da Faculdade, corresponde ao conceito de magistério docente. E a título de esclarecimentos transcreve decisões dêste Conselho, em reuniōes realizadas em 6 de setembro de 1956 e 13 de setembro de 1956.

"A partir da presente data, todos os médicos que exercerem neste Hospital funções gratificadas cono médicos-auxiliares ou contratados passarão a ter seus respectivos titulos apostilados com a discriminação que exercem função de Auxiliares de Ensino. A presente decisão decorre das disposições expressas do Decreto $\mathrm{n}^{\circ} 13.635$ de 27 de outubro de 1943, no seu art. 2 ${ }^{\circ}$, letra " $b "$ ". Decido ainda que os médicos contratados e auxiliares dêste Hospital, os primeiros no ato do contrato e os segundos em declaração escrita endereçada a êste Conselho, deverão declarar se não acumulam êsse cargo com outro cargo público, e no caso afirmativo qual o cargo que acumula fora do nosocômio". Reunião realizada em 6 de setembro de 1956 . "Em aditamento rà decisão dêste Conseliıo referente à condição de serem us médicos auxiliares e contratados admitidos como Auxiliares de Ensino decide ainda mais que, pira efetivação dos respectivos contratos ou admissão nas respectivas funções de médicos auxiliares seja exigido, doravante, o titulo de Assistente Extranumerário da Faculdade, adstritos às Cátedras pelas quais tenham sido indicados". Reunião realizada em 13 de setembro de 1956".

Por outro lado, a documentação constante do processo revela que o interessado exerce "atividades didáticas e de treinamento de alunos, na Clínica Ortopédica e Traumatológica" e nos Cursos de Aperfeiçoamento, como integrante do grupo de Reumatologia (fls. 13), colaboração "nos trabalhos diários de ambulatório e de enfermaria, no sentido de propiciar condiçóes suficientes para o ensino da especia1:dade a alunos da Faculdade de Medicina, a médicos estagiários, a neédicos internos, a participantes de cursos de especialização e de bôlsas de estudos, assim como contribui para a realização de cursos de Reumatologia eventualmente promovidos em outros ambientes cientificos".

A compatibilidade horária está demonstrada nas declaraçốes oficiais de fls. 37 e 47 , pelas quais se verifica que, no cargo federal, presta o interessado as 30 horas semanais do trabalho a que está obrigado de conformidade com a legislação em vigor. 
Nestas condições, somos por que se considere licita a situação descrita no processo, desfeitas que estão quaisquer dúvidas que possam advir quanto à natureza do cargo de Médico-Auxiliar do Hospital das Clinicas o qual em virtude de sua denominação poderá parecer técnico-cientifico, mas que o estudo efetuado demonstrou ser de at:vidades docentes.

C.A.C., 10 de abril de 1964. -Zola Maria Fraga, Relator. - José Medeiros. - Milton de Carvalho Briggs. - Célio Fonseca. - Aluisio Xatier Moreira - Corsindio Monteiro da Silva.

Submeto, nos têrmos do $\S 3$ io art. 15, do Decreto $n^{\circ} 35.956$, de 2-8-54, o presente parecer à aprovação do Sr. Diretor-Geral do D.A.S.P.

Brasilia, 14 de abril de 1964 . José Medeiros, Presidente da Comissão de. Acumulação de Cargos.

Aprovo - Em 24-4-61. - Francisco de Carvalho Mello.

(Diário Oficial de 15 de maio de 1964).

\section{PROCESSO N $N \quad 24.242-63$}

Não é licito a acumulação de dois cargos de Médico, embora, em razão de um dêles, seja conferida ao respectivo ocupante atribuiçócs de magistério, o que constitui. mero désvio de funçốes, não considerado para descaracterizar o cargo técnico-cientifico.

\section{PARECER}

Trata o presente processo da situação funcional de Pedro Ad-Vincula Veado. Filho, quanto ao problema de acumulação de cargos .

2. O interessado vinha exercendo as funções de Médico no Instituto de Aposentadoria e Pensões dos Indus- triários, na Delegacia de Minas Gerais, tendo sido equiparado aos axtranumerários-mensalistas, de acôrdo co:n a Lei $n^{2} 3.483$, de 1958, e conseqüientemente aos funcionários efetivos, na forma da Lei $\mathrm{n}^{\circ} 2.284$, de 1954 .

3. Esclarece o processo, outrossim. ocupar o interessado o cargo de Médico Clinico do Estado de Minas Gerais, tendo sido designado para lecionar a disciplina "Anatomia e Fisiologia" em curso da Escola de Saúde Pública da Secretaria de Saúde e Assistência daquele Estado.

4. Não há dúvida, porém, de que o interessado ocupa, no Estado de Ml. nas Gerais, o cargo de Médico Clinico, de natureza técnico-científica, porquanto a eventual designação para lecionar na Escola de Saúde Pública não transfigura o caráter daquele cargo. Trata-se, evidentemente, de desvio ternporário e ocasional de atribuições, razão pela qual não se pode configurar - cargo como de magistério.

5. De fato, casos semelhantes as de que cogita êste processo já mereceram estudos desta Comissão, dentre os quais os constantes dos processos DASP ns . 3.005-62 e 16.034 de 1963 . cujos pareceres foram publicados nos Diários Oficiais de 14 de maio de 1962 e 2 de outubro de 1963 , respectivamente, tendo sempre concluido at: o exercício esporádico de atividade de magistério é irrelevante para o exame da acumulação do funcionário - "porquanto permanecem inalteráveis os vin culos que o prendem ao cargo de
médico".

6. Em consonância com essa orizntação, que se fundamenta em Iprincípios legais, a situação do interessado não se enquadra em nenhuma das exceções estabelecidas, a regra proibitiva do art. 185 da Constituição, visto zomo se refere ao exercicio concorrente de dois cargos de Médico, ambos técnicocientificos.

7. Com efeito, a incidência de acumulação de cargos permitida legalmente estaria condicionada à existência comprovada de um cargo de magisté- 


\section{JuRisprudêNCIA AdMinistrativa - Pareceres 105}

rio o que não ocorre na espécie, a ser exercido concorrentemente com outro cargo técnico-cientifico ou também de magistério.

8. Nestas condições, somos pela declaração da ilegitimidade da acumulação de cargos exposta no presente processo, devendo ser exigida imediata opção do interessado, sem prejuizo da providência prevista no art. 193 da Lei $\mathrm{n}^{\circ} 1.711$, de 28 de outubro de 1952 .

C.A.C., 24 de abril de 1964. José Medeiros, Relator. - Célio Fonseca. - Zola Maria Fraga. - Aluisio
Xavier Moreira. - Corsindio Monteiro da Silva.

Submeto, nos têrmos do $\S 3^{\circ}$ do artigo 15 , do Decreto $n^{\circ} 35.956$, de 2 de agôsto de 1954 , o presente parecer à aprovação do $\mathrm{Sr}$. Diretor-Geral do DASP.

Brasilia, 23 de abril de 1964. - José Medeiros, Presidente da Comissão de Acumulação de Cargos.

Aprovo - 30 de abril de 1964. Francisco de Catvalho Mello.

(Diário Oficial de 19 de maio de 1964). 